\title{
The Relationship between Emotional Intelligence and Academic Achievements in Males and Females in Egyptian Context ${ }^{*}$
}

\author{
Mustafa Ali Khalaf Ali \\ Minia University, Minia, Egypt
}

\begin{abstract}
The present study examines the relationship among emotional intelligence, achievement, and gender. The sample consists of 121 participants at a public university in North Upper Egypt called Minia University. The Wong \& Law's (2002) emotional intelligence scale has been used in this study. Confirmatory factor analysis has been adopted to verify the structure validity of the EI scale. Results of confirmatory factor analysis showed that the four-factor model fits well and its results meet the criteria for goodness of fit indices $(>0.90)$ and root mean score residual $(<0.05)$. Cronbach Alpha indicated high reliability of the scale. Positive correlation was found between academic achievement and self emotional appraisal, regulation of emotion, use of emotions, and total emotional intelligence score. There was no significant difference between males and females in emotional intelligence in the total score of EI scale and its subscales. Only two dimensions (regulation of emotions \& self emotions appraisal) predicted academic achievement.
\end{abstract}

Keywords: emotional intelligence, academic achievement, Egyptian students, gender

\section{Introduction}

Recent years have seen an explosion of deep interest, debate, and even controversy regarding concepts related to emotional intelligence (EI). Unfortunately, the controversy over defining emotional intelligence, recognizing differences in its conceptual and empirical base, and determining the appropriateness of its practices has kept emotional intelligence from its rightful integrative place, with respect to educating youth (McLaughlin, 2008). Emotional intelligence can be defined as a construct including a set of abilities such as being able to be motivated and persist in the face of frustration, controlling impulses and delaying gratification, regulating ones' moods and preventing distress from swapping the ability to think and hope (Goleman, 1995).

In a review of literature conducted by (Stys \& Brown, 2004), emotional intelligence has been found to be a predictor of life satisfaction, healthy psychological adaptation, positive interaction with peers and family, and higher parental warmth. Lower emotional intelligence has also been found to be associated with violent behavior, illegal use of drugs and alcohol, and participation in delinquent behavior. Research on the predictive significance of EI over IQ was spurred by Goldman's initial publication on the topic which claimed that emotional intelligence could be "as powerful, and at times more powerful, than IQ" (Goleman, 1995).

\footnotetext{
*Acknowledgments: I wish to express my sincere appreciation to Prof. Dr. Muhammad Abd-elghani Teleb, Emeritus Prof. of English Language, and Ph.D. in linguistics, University of Illinois, USA, who revised and corrected an earlier version of this manuscript. I am also deeply grateful to the participants for their co-operation.

Mustafa Ali Khalaf Ali, Lecturer, Dept. of Educational Psychology, College of Education, Minia University.
} 
Subsequently, scholars started to investigate emotional intelligence and academic achievement (e.g., Barisonek, 2005; Fahim \& Pishghadam, 2007; Walker, 2006). Fahim and Pishghadam (2007) found that academic achievement was strongly associated with several dimensions of emotional intelligence. It has been accepted that scholars' attention should be directed to the issue of affective factors in educational settings since emotions and emotional factors have a crucial role in students' personality and academic life (Alasmari, 2014). Much research has been conducted in the field of (EI) assuming that emotionally intelligent persons are successful in both life and education (e.g., Goleman, 1995). In the same context, EI was found to be useful in classrooms and in cognitive tasks (Shuttes, Schuetplez, \& Malouff, 2001; Petrides, Friderickson, \& Furnham, 2004). Ogundokun and Adeyemo (2010) asserted that it is necessary for the curriculum developers to integrate EI into the school curriculum depending upon the fact that EI is a significant factor in learning and strong predictor of academic achievement (p. 137).

\section{Literature Review}

Proponents of the EI concept argue that EI affects one's physical and mental health as well as one's career achievements. According to Goleman (1995), EI consists of five components: knowing our emotions (self-awareness), managing them, motivating ourselves, recognizing emotions in others (empathy), and handling relationships. Those with low EI are rigid, inflexible, need rules and structure to feel secure, so various studies have found that emotional intelligence is somehow vital for success and might affect students' achievement The fact that much of the variance in academic success remains unaccounted for by affective variables (e.g., emotional intelligence) has encouraged researchers to investigate additional predictors. In recent years, there has been increased attention to the role of EI and social competency in academic success (Parker, Saklofske, Wood, \& Collin, 2009).

Despite the fact that cognitive abilities are important predictors of success in pre-university education, their importance decreases notably in the university setting (Parker et al., 2009). Rode et al. (2007) stated that emotional intelligence is a good predictor of academic success. Parker, Duffy, Wood, Bond, and Hogan (2005) posited that academically successful students outperformed the unsuccessful students in emotional intelligence.

Preeti (2013) stated that academic achievement without emotional intelligence does not indicate future success and absence of emotional intelligence also indicates weak personality and ability to build relations at working place as well as in schools. Advocating the same trend, Parveen, Malik, and Aziz (2012) concluded that the level of emotional intelligence contributes to and enhances the cognitive abilities of students. Abdel-hafez and Hassan (2011) asserted that emotional intelligence is nowadays considered to be a vital element in achieving success and recommended to start teaching its components in Egyptian schools and universities so as to raise the levels of students' achievement. Festus (2012) recommended that there is a need to include an emotional intelligence course at schools.

Higher academic achievers showed higher levels of emotional intelligence (Abdel-hafez \& Hassan, 2011; Morales \& Esther, 2013). Alasmari (2014) investigated the effects of EI on academic achievement of 200 male and female English language undergraduates in Saudi Arabia. It was found that higher EI levels of female undergraduates had positive impact on their performance in English language tests. Females also scored better in EI constructs: intrapersonal, interpersonal, stress management and general good. The study recommended that if EI skills are strengthened in both genders, they may display better levels of personal and academic achievements. 
Dolores, Rosal, Norma, Karina, and Maryurena (2013) indicated a significant relationship between emotional intelligence and performance; in addition, a significant relationship between emotional intelligence and intellectual capacity was also detected. Preeti (2013) revealed a significant correlation between emotional intelligence and academic achievement. He concluded that teaching emotional and social skills at school not only positively influence academic achievement during the year when these were taught but also leaves the impact in long term achievement. Durgut, Gerekan, and Pehlivan (2013) found that components of emotional intelligence (independency, self-fulfillment, social responsibility, flexibility and problem solving) had an impact on achievement. Therefore, it has been concluded that some sub-components of the emotional intelligence are influential on accounting achievement. Festus (2012) stated that there was a significant low positive relationship between the emotional intelligence of students and their academic achievement. Yahaya et al. (2012) revealed significant correlation between self awareness, emotional management, and empathy with academic achievement. Only three elements of emotional intelligence which are self-awareness, self motivation and empathy accounted for $8.7 \%$ of variation in academic achievement. Fayombo (2012) found that emotional intelligence contributed $40 \%$ to the variance in academic achievement and thus it was a better predictor of academic achievement than gender. Nasir and Masrur (2010) conducted a correlational study in which emotional intelligence was found to be a significant predictor of academic achievement.

On the other hand, findings of a study conducted by Kashani, Azimi, and Vaziri (2012) indicated that there was no significant association between emotional intelligence and students' achievement scores. Ahammed, Abdullah, and Hassane (2011) examined the relationship between EI and academic success of 204 undergraduate students in United Arab Emirates universities. The results of the correlation analysis revealed that academic success was not related to EI. Pope, Roper, and Qualter (2012) examined the relationship between overall EI and specific EI competencies in 135 undergraduate psychology students in the UK. Results showed that total EI did not significantly predict final APM, specific EI competencies (conscientiousness, adaptability, empathy, organizational awareness, and building bonds) significantly predicted average percentage mark (APM) after controlling for gender.

In the same context, Michel and Legrand (2012) asserted that EI had no influence on performance. These findings question the recent spread of EI training programs within schools. In university context, Kashani et al. (2012) found no significant association between emotional intelligence and achievement. Lawrence and Deepa (2013) proved that there was no significant correlation between emotional intelligence and academic achievement of high school students. Thus, the significant amount of controversy surrounding emotional intelligence supports the need for further research (Stys \& Brown, 2004).

\section{Comment on the Literature Review}

Many studies asserted the positive effects of emotional intelligence on achievement and performance (e.g., Abdel-hafez \& Hassan, 2011; Dolores et al., 2013; Durgut, Gerekan, \& Pehlivan, 2013; Parker et al., 2005; Preeti, 2013; Rode et al., 2007). In addition, results of other studies showed that cognitive abilities are enhanced through supporting emotional intelligence (e.g., Parven et al., 2012). The relation between emotional intelligence and achievement was low but significant in other studies (e.g., Festus, 2012). On the other side, some studies reached insignificant correlation between emotional intelligence and achievement (e.g., Ahammed et al., 2011; Kashani et al., 2012; Lawrence \& Deepa, 2013; Michel \& Legrand, 2012; Pope et al., 2012). 


\section{Gender Differences in EI}

Competing evidence exists surrounding whether or not males and females differ significantly in general levels of emotional intelligence. Goleman (1998) asserts that no gender differences in EI exist, admitting that while men and women may have different profiles of strengths and weaknesses in different areas of emotional intelligence, their overall levels of EI are equivalent. However, studies by Mayer and Geher (1996), Mayer, Caruso, and Salovey (1999), and more recently Mandell and Pherwani (2003) have found that women are more likely to score higher on measures of emotional intelligence than men, both in professional and personal settings (Stys \& Brown, 2004). Nasir and Masrur (2010) found insignificant difference among male and female students except on stress management subscale where male students scored higher than female students. Parveen et al. (2012) found that male and female adolescents do not differ significantly on academic achievement. Whereas Alasmari (2014) indicated that females also scored better in EI constructs: intrapersonal, interpersonal, stress management and general good. Parveen et al. (2012) found no significant difference between males and females in emotional intelligence.

\section{The Present Study}

In recent years, there has been an increasing interest in the role of emotional intelligence in both the academic success of students and their emotional adjustment. However, promotion of emotional intelligence in schools has proven a controversial and challenging pursuit. Furthermore, research findings in this area have been inconsistent at best (Humphrey, Curran, Morris, Farrell, \& Woods, 2007). Psycho-educational researchers have often suggested that emotional intelligence (EI) is critical to academic success, yet there is hardly any research that has ever addressed this question in university students in the Egyptian context. The problem of this research revolves around investigating the correlation that may exist among EI, gender and academic achievement of college students. The controversy concerning the role of EI in academic performance and the inconsistent differences in EI related to gender encouraged the researcher to examine that issue in a university located in Upper Egypt where there are few studies that tackled this point with undergraduates. So this study is intended to see whether there is a relationship between emotional intelligence and academic achievement or not. The lack of studies investigating the correlation between emotional intelligence and achievement of college male and female students (e.g., Ali, 2013) motivated the present researcher ton address this point.

\section{Objectives of the Present Study}

Examining the structure validity of the Wong \& Law's emotional intelligence scale (WLEIS) in the Egyptian context.

Examining the correlation relationship between EI and academic achievement of college students.

Knowing which of EI dimensions can predict academic achievement.

Exploring the difference in EI between males and females.

\section{Hypotheses of the Present Study}

(1) The Wong \& Law's emotional intelligence scale (WLEIS) retains its factorial structure in the Egyptian context.

(2) There is a significant correlation between EI and academic achievement of college students.

(3) Emotional intelligence can predict academic achievement.

(4) There is a significant difference between males and females in EI. 


\section{Methodology}

\section{Measurement}

Emotional intelligence was assessed using Wong \& Law's (2002) emotional intelligence scale. The instrument consisted of 16 items and few questions about background information like gender, age, faculty, specialization, etc. It took 15-20 minutes to be completed. (WLEIS) was designed as a short measure of EI assessing four dimensions: self emotion appraisal (SEA) (e.g., I have good understanding of my own emotions), appraisal of others' emotion (AOE) (e.g., I am sensitive to the feelings and emotions of others), use of emotion (UOE) (e.g., I would always encourage myself to try my best), and regulation of emotion (ROE) (e.g., I have good control of my own emotions). The (WLEIS) was translated into Arabic by a bilingual Egyptian researcher and blindly back-translated by another bilingual person to ensure language equivalence. The translated (WLEIS) retained the original 16 items and the 7-point likert-type response format ( $7=$ "Strongly agree" to $1=$ "Strongly disagree").

Achievement scores of the participants were taken from the end of year examinations. Each student had a total score that reflects his performance throughout the year. This score reflects his performance in all subjects taught at the academic year 2013/2014.

\section{Participants}

Subjects of the present study included 287 students recruited as a pilot sample for computing validity and reliability of the scale. They were randomly selected. $48 \%$ of the sample consisted of male students and $52 \%$ of female students with the age ranges (19-30) years. Their mean age was 26.94 years $(S D=5.04)$. They were selected by using the random sampling method. Then 121 students ( 58 males, 63 females) participated in the main study for verifying the hypotheses. Their ages ranged between (19-30) years. They were enrolled at a public university in North Upper Egypt called Minia University.

\section{Procedures}

The sample mainly comprised of those students who were willing to participate in the study and they properly completed the given scale. The collection of data was during the classes given to students in the laboratory of educational psychology department in college of education at Minia University. Initially 200 respondents were personally contacted in their free time. They were briefed about how to rate the responses. Most students accurately completed the scale; however, some questionnaires were returned incompletely or invalidly filled. They were not included in the sample. The data about students' academic achievements was collected from their academic records in the university.

\section{Results}

\section{Psychometric Properties of the (WLEIS)}

Structure Validity. Confirmatory Factor Analysis. Confirmatory factor analysis (CFA) was conducted on 16 items to examine the structure validity. Results of confirmatory factor analysis are presented in Table 1.

Table 1

CFA Results of the Four-Factor Model $(N=287)$

\begin{tabular}{llllll}
\hline Model & $\chi^{2}$ & RMSEA & GFI & AGFI & CFI \\
\hline Four factor & 3.734 & 0.055 & 0.993 & 0.967 & 0.978 \\
\hline
\end{tabular}


Table 1 shows that the four-factor model fits well and results meet the criteria for goodness of fit indices $(>0.90)$ and root mean score residual (RMR < 0.05) (see McDonald \& Marsh, 1990) which means the (WLEIS) retained a four factor structure in the Egyptian university students sample.

Reliability. Internal Consistency and Item Homogeneity. Internal consistency was conducted as an indicator to validity (see Table 2). The correlation coefficients were computed between each item and the total score of the scale.

Table 2

Internal Consistency, Alpha $\alpha$ and MIC of Dimensions of the WLEIS

\begin{tabular}{|c|c|c|c|c|c|c|c|}
\hline $\begin{array}{l}\text { Factor } 1 \text { self } \\
\text { emotions appraisal } \\
\text { SEA }\end{array}$ & $R \&$ sig. & $\begin{array}{l}\text { Factor } 2 \text { appraisal of } \\
\text { others' emotions } \\
\text { AOE }\end{array}$ & $R \&$ sig. & $\begin{array}{l}\text { Factor } 3 \text { regulation } \\
\text { of emotions } \\
\text { ROE }\end{array}$ & $R \&$ sig. & $\begin{array}{l}\text { Factor } 4 \text { use of } \\
\text { emotions } \\
\text { UOE }\end{array}$ & $R \&$ sig. \\
\hline 1. & $0.739^{* *}$ & 5. & $0.658^{* *}$ & 9 & $0.774^{* *}$ & 13 & $0.755^{* *}$ \\
\hline 2. & $0.793^{* *}$ & 6. & $0.759^{* *}$ & 10 & $0.639^{* *}$ & 14 & $0.832^{* *}$ \\
\hline 3. & $0.764^{* *}$ & 7. & $0.564^{* *}$ & 11 & $0.749^{* *}$ & 15 & $0.779^{* *}$ \\
\hline 4. & $0.645^{* *}$ & 8. & $0.764^{* *}$ & 12 & $0.752^{* *}$ & 16 & $0.799^{* *}$ \\
\hline
\end{tabular}

Note. $N=287,{ }^{* *} p<0.01$.

Table 3

Inter-Correlation Between Subscales, Alpha $\alpha$ and Mean Inter-item Correlation

\begin{tabular}{lllll}
\hline & SEA & AOE & UOE & ROE \\
\hline$\alpha$ Alpha & 0.72 & 0.80 & 0.70 & 0.63 \\
MIC & 0.39 & 0.50 & 0.38 & 0.30 \\
SEA & 1 & $0.191^{* *}$ & $0.241^{* *}$ & $0.197^{*}$ \\
AOE & $0.191^{* *}$ & 1 & $0.158^{* *}$ & $0.129^{*}$ \\
UOE & $0.241^{* *}$ & $0.158^{*}$ & 1 & $0.396^{*}$ \\
ROE & $0.197^{* *}$ & $0.129^{*}$ & $0.396^{* *}$ & 1 \\
\hline
\end{tabular}

Note. ${ }^{* *} p<0.01, \stackrel{*}{p} p<0.05$.

\section{MIC: Mean Inter-Item Correlation}

It can be observed from Tables 2 and 3 that correlation coefficients ranged from 0.564 to 0.832 , and all correlations were significant at level of 0.01 . The alpha reliability coefficient of total EI scale is 0.78 and those of its 4 sub-scales range from 0.63 to 0.80 . These results indicate that the instrument has a high internal consistency. Taken together, the results of Table 2 and 3 show that the subscales of the EI measure had acceptable reliability estimates.

\section{Correlation among EI, Achievement \& Gender}

Table 4

Pearson Correlation Between Dimensions of EI and Achievement

\begin{tabular}{llllll}
\hline Variables & SEA & AOE & ROE & UOE & Total EI \\
\hline Achievement & $0.315^{* *}$ & 0.157 & $0.385^{* *}$ & $0.228^{*}$ & $0.443^{* *}$ \\
\hline
\end{tabular}

Note. $N=121, \stackrel{* *}{p} p<0.01, \stackrel{*}{p}<0.05$.

Table 4 shows that statistically significant correlation between achievement and the total score of EI and its dimensions namely self emotional appraisal SEA, regulation of emotion ROE, and use of emotion UOE, while the correlation between achievement and others emotional appraisal AOE wasn't significant. 
Table 5

Results of Stepwise Multiple Regression Analysis

\begin{tabular}{llllllll}
\hline Model & $B$ & $\beta$ & $R^{2}$ & $\Delta R^{2}$ & $T$ & Sig. & $F$ \\
\hline Model 1 & & & & & & \\
\hline ROE & 7.41 & 0.39 & 0.148 & 0.141 & 4.55 & 0.000 & 20.72 \\
\hline Model 2 & & & & & & & \\
\hline ROE & 6.23 & 0.32 & & & 3.78 & 0.000 & 14.44 \\
SEA & 4.83 & 0.23 & 0.197 & 0.183 & 2.67 & 0.009 & \\
\hline
\end{tabular}

Note. $N=121$.

It is observed from Table 5 that only two dimensions of EI could predict achievement of college students.

Table 6

Gender Differences in EI (58 Males, 63 Females)

\begin{tabular}{lllllll}
\hline Variables & Group & $M$ & $S D$ & $D F$ & $T$ & Sig. \\
\hline \multirow{2}{*}{ SEA } & Males & 21.88 & 3.56 & 119 & 0.285 & 0.776 \\
& Females & 22.06 & 3.53 & & & \\
OEA & Males & 21.64 & 3.25 & 119 & 0.495 & 0.622 \\
& Females & 21.33 & 3.50 & & & \\
ROE & Males & 20.67 & 3.97 & 119 & 1.83 & 0.070 \\
& Females & 19.35 & 3.98 & & & \\
UOE & Males & 17.84 & 4.48 & 119 & 0.985 & 0.327 \\
Total & Females & 16.98 & 5.08 & & & \multirow{2}{*}{0.218} \\
EI & Males & 82.03 & 9.24 & 119 & 1.24 & \\
\hline
\end{tabular}

Table 6 indicates that no statistically significant difference was found between male and female students in $\mathrm{EI}$ and its dimensions because the computed $t$-values were less than the tabulated $t$-values. This means that EI doesn't signify according to the gender of the student.

\section{Discussion}

The aim of the present study is to investigate the relationship among EI, academic achievement and gender in a sample of university students in Egyptian context. University in Egypt is an important place to study such relationship because it represents an environment that induces significant amounts of stress and has implicit and explicit study demands. The significant correlation that was found between two subscales of EI and academic achievement of university students should attract the attention of curriculum developers to get familiar with the influence those two dimensions on achievement. Results of this research may be useful in resolving the controversy concerning the avail of EI training in increasing the level of students' achievement. The significant correlation between regulation of emotions and academic achievement can be explained by the fact that emotional intelligence helps person to restrain negative feelings such as anger, self-doubt, stress, and anxiety and instead focus on positive ones such as confidence, empathy and congeniality (Sunil \& Rooprai, 2009). Self emotion appraisal was related to academic achievement for two reasons. First, academic achievement involves a great deal of self-dependence and pressure. Second, majority of academic work in university life is self directed, requiring high levels of self control. Therefore, individuals who are properly aware of their emotions would perform better academically. 
The significant correlation between regulation of emotions and achievement can be explained by the emotional competence of students. Emotional competence is viewed as the ongoing product of emotional development and social learning, both of which can take place in educational settings and contribute to academic achievement (Matthews, Zeidner, \& Roberts, 2002). Emotional competence enables higher EI students to control and regulate their emotions during study and class times; consequently they can pursue their academic goals and achieve better than lower EI students. This result support findings reached by Parveen et al. (2012) and Fayombo (2012) which indicated that if students are emotionally unstable, it will affect their academic performance and if they are emotionally stable, they will definitely highlight good academic results.

It is possible that emotional intelligence skills such as self emotional appraisal and regulation of emotion are highly essential to academic success, for instance, a student who is aware of his emotions and has the ability to regulate these emotions could use such skill to get rid of stress and anxiety associated with tests and examination apprehension. Furthermore, the ability to use emotions in facilitating thinking and decision making may help students to seek academic help from their instructors, friends and librarians. Higher emotionally intelligent students have the ability to evaluate others' emotions; thus, they could display interpersonal skills which enable them to have good and resourceful relationships and effectively communicate with others in the academic settings. The significant correlation between the total score of EI scale and achievement is consistent with the findings reached by (Nasir \& Masrur, 2010; Nelson \& Nelson, 2003; Parker et al., 2004; Preeti, 2013; Rode et al., 2007; Yahaya et al., 2012). On the other hand, other results of certain studies were inconsistent with this finding such as (Ahmmed et al., 2011; Kashani et al., 2012) which reported non-significant correlation between EI and achievement.

Regression analysis was performed for analyzing whether emotional intelligence is a significant predictor of academic achievement. The results of regression analysis indicated that only two subscales of emotional intelligence significantly predict academic achievement and they accounted for almost $19.7 \%$ of the variance in academic achievement. The other two subscales (appraisal of others' emotions \& use of emotions) were not significant because of the conservative styles of socialization in the Egyptian context prevent students from the overt expression of their emotions towards others. Many females consider that appraisal of others emotion as a violation of good manners of conduct and morals. It is worth noting that females constitute a large number of the participants and those females are shy and ashamed. They find difficulties in demonstrating or using their feelings freely. These findings are in line with the findings of the previous studies done by (Ahmad, 2011; Mayer \& Salovey, 1997; Naoreen \& Gujjar, 2009; Nasir \& Masrur, 2010; Ramazan, Gujjar, \& Ahmad, 2011).

The non-significant differences between males and females in EI mean that the levels of EI were relatively similar across male and female students. This finding may be explained by the gender socialization practices in the Egyptian society. It is possible that Egyptian males and females have been socialized so that they acquire and practice roughly the same emotional skills in similar manners. Due to the age and experience, males and females may similarly have improved emotional intelligence skills, and this may be a possible reason why there are no differences among them in EI. It is also possible that females of this age and culture may no longer hold on to the stereotype of an emotionally reserved and constricted female image. Owing to the openness of the Egyptian society to the social media and women's ambition to be equal in everything with males, they could have acquired the ability to express their own emotions and appropriately evaluate those of others. 
Several studies have reported no gender differences in EI (e.g., Parveen et al., 2012; Stys \& Brown, 2004). The present study, in consistence with some previous studies, found no significant differences among males and females in EI. The non-significant differences among males and females in this study may be due to the fact that they come from nearly similar social economic and educational background. This finding is inconsistent with what mentioned by Gardner (1999) who posited that emotional intelligence varies by gender and age. The studies that found gender differences in EI explained the significant differences in EI between genders by the interpretation that women have high score on the emotional self-awareness, which incorporates the recognition and understanding of one's emotions. They have the ability to recognize emotions, initiate and maintain emotionally close and intimate relationships. This can be explained by the women's gender role which prescribes paying more attention to and analyzing one's own emotions.

\section{Conclusions}

The high level of emotional intelligence can help calm the mind and thus to increase the absorption of information received. Thus, it will contribute to students' academic achievement as a result. It is recommended that students' academic achievement should be enhanced with the use of emotional intelligence training. Emotional intelligence should be noted not only for academic interest but also of future success in life. With the aim of building a resilient and competent individual in the face of globalization and changing demands, efforts to increase students' emotional intelligence should be considered during the process of teaching and learning in the classroom (Bharti \& Sidana, 2012). Emotional intelligence helps in positive classrooms in which relationships among teachers and students are characterized by warmth and kindness which facilitate learning (Nasir \& Masrur, 2011).

So it is important for university students to be equipped with such emotional and social skills that are essential for a successful practical life because it is widely known that the academic success is not the sole requirement for work and life success.

\section{Limitations of the Present Study}

Although the findings of this study increase our understanding of the relationship between dimensions of EI and academic achievement, these results should not be taken for granted because this research was confined to some limitations; the first and most important limitation is that the respondents were selected from College of Education at Minia University and the relatively small sample size may result in lack of representation of the population and consequently lack of generalization of the findings. To generalize those results, the research should be repeated with larger number of students in different educational settings. The second limitation was the self-reported EI scale. Although self ratings of EI remain the standard used by most researchers, future studies are needed to assess EI through direct observation by the researcher himself/herself or by significant others. Despite the limitations, the results may add to the body of literature examining EI among university students in general and Egyptian ones in particular.

\section{Future Research}

Further studies could examine the relationship between EI and achievement across different educational levels and cultural contexts. In addition, the role of EI training in the improvement of achievement levels and stress management need to be explored in more qualitative ways. 


\section{References}

Abdel-hafez, H., \& Hassan, E. (2011). Association between foreign language learning anxiety and emotional intelligence and their mediating effect on the academic achievement of Egyptian non-English majors. Journal of Research in Education \& Psychology, 24, 1-42.

Ahmad, S. (2011). The relationship between the emotional intelligence and the academic achievement of prospective teachers. The Asian conference on education official conference proceedings (pp. 580-589), Osaka, Japan.

Ahammed, S., Abdullah, S., \& Hassane, S. (2011). The role of emotional intelligence in the academic success of United Arab Emirates university students. International Education, 4, 7-25.

Alasmari, A. (2014). Emotional intelligence and academic achievement: A comparative gender-based study of undergraduate English language learners in Saudi Arabia. Journal of Education \& Practice, 5, 178-190.

Ali, M. (2013). Emotional intelligence of general educational diploma students. Journal of Research in Education\& Psychology, 26(2), 206-233.

Barisonek, E. (2005). The relationship between emotional intelligence, academic achievement and academic production among third and sixth grade students (Unpublished Master's thesis, The State University of New York).

Bharti, R., \& Sidana, J. (2012). A study of emotional intelligence in relation to academic achievement and academic stress of student-teachers. Indian Streams Research Journal, 2(9), 1-6.

Brasseur, S., Gre'goire, J., Bourdu, R., \& Mikolajczak, M. (2013). The profile of emotional cmpetence (PEC): Development and validation of a self-reported measure that fits dimensions of emotional competence theory. PLOS, 8(5), $1-9$

Dolores, V., Rosal, B., Norma, R., Karina, V., \& Maryurena, L. (2013). Emotional intelligence and its relationship with gender, academic performance and intellectual abilities of undergraduates. Electronic Journal of Research in Educational Psychology, 11, 395-412.

Durgut, M., Gerekan, B., \& Pehlivan, A. (2013). The impact of emotional intelligence on the achievement of accounting subject. International Journal of Business and Social Sciences, 4, 64-71.

Eisenberg, N. (1994). Empathy, in Ramachaudran (Ed.). Encyclopedia of Human Behavior, 2, 247-250.

Fahim, M., \& Pishghadam, R. (2007). On the role of emotional, psychometric, and verbal intelligences in the academic achievement of university students majoring in English language. Asian EFL Journal, 9, 240-253.

Fayombo, G. (2012). Emotional intelligence and gender as predictors of academic Achievement among Some university students in Barbados. International Journal of Higher Education, 1, 102-111.

Festus, A. (2012). The relationship between emotional intelligence and academic achievement of senior secondary students in the federal capital territory. Abuja, Journal of Education \& Practice, 3, 13-19.

Gardner, H. (1999). Intelligence reframed: Multiple intelligences for the 21st century. New York: Basic Books.

Gallagher, E., \& Vella-Brodrick, D. (2008). Social support and emotional intelligence as predictors of subjective well-being. Personality and Individual Differences, 44, 1551-1561.

Goleman, D. (1998). Working with emotional intelligence. New York: Bantam Books.

Goleman, D. (1995). Emotional Intelligence: Why it can matter more than IQ. New York: Bantam Books.

Humphrey, N., Curran, A., Morris, E., Farrell, P., \& Woods, K. (2007). Emotional intelligence and education: A critical review. Educational Psychology, 27, 235-254.

Kashani, L., Azimi, L., \& Vaziri, S. (2012). Relationship between emotional intelligence and educational achievement. Procedia Social and Behavioral Sciences, 69, 1270-1275.

Lawrence, A., \& Deepa, T. (2013). Emotional intelligence and academic achievement of high school students in Kanyakumari District. International Journal of Physical and Social Science, 3, 101-107.

Leroy, V., Grégoire, J., Magen, E., Gross, J., \& Mikolajczak, M. (2012). Resisting the sirens of temptation while studying: Using reappraisal to increase focus, enthusiasm, and performance. Learning and Individual Differences, 22, 263-268.

Mandell, B., \& Pherwani, S. (2003). Relationship between emotional intelligence and transformational leadership style: A gender comparison. Journal of Business and Psychology, 17(3), 387-404.

Matthews, G., Zeidner, M., \& Roberts, R. (2002). Emotional intelligence: Science and myth. Cambridge: MIT Press.

Mayer, J., \& Geher, G. (1996). Emotional intelligence and the identification of emotion. Intelligence, 22, 89-113.

Mayer, J., Caruso, D., \& Salovey, P. (1999). Emotional intelligence meets standards for traditional intelligence. Intelligence, 27, 267-298. 
Mayer, J., \& Salovey, P. (1997). What is emotional intelligence? In P. Salovey, \& D. Sluyter (Eds.), Emotional development \& EQ. 30.31. New York: Basic Books.

McDonald, R., \& Marsh, H. (1990). Choosing a multivariate model: Non-centrality and goodness of fit. Psychological Bulletin, $107,247-255$.

McLaughlin, C. (2008). Emotional well-being and its relationship to schools and classrooms: A critical reflection. British Journal of Guidance and Counseling, 36, 353-366.

Michel., H., \& Legrand, J. (2012). Creativity, emotional intelligence and school performance in children. International Journal of Educational Research, 53, 264-268.

Morales, J., \& Esther, L. (2013). The impact of students' perceived emotional intelligence, social attitudes and teacher expectations on academic performance. Electronic Journal of Research in Educational Psychology, 11, 75-98.

Nasir, M., \& Masrur, R. (2010). An exploration of emotional intelligence of the students of IIUI in relation to gender, age, and academic achievement. Bulletin of Education \& Research, 32, 37-51.

Nasir, M., \& Masrur, R. (2010). An exploration of emotional intelligence of the students of IIUI in relation to gender, age, and academic achievement. Bulletin of Education \& Research, 32, 37-51.

Nelson, D., \& Nelson, K. (2003). Emotional intelligence skills: Significance factors in freshmen achievement and retention. A Paper presented at The American Counseling Association Conference, Marsh, 21-25, Accessed at http://eric.ed.gov/

Naoreen, B., \& Gujjar, A. (2009). A comparative study to measure and compare the emotional intelligence of the students of the Islamia University of Bahawalpur on selected variables. I-manager's Journal on Educational Psychology, 21(3), 61-69.

Ogundokun, M., \& Adeyemo, D. (2010). Emotional intelligence and academic achievement: The moderating influence of age, intrinsic and extrinsic motivation. The African Symposium "An online Journal of The African Educational Research Network", 10(2), 323-342.

Parker, J., Salofske, D., Wood, L., \& Collin, T. (2009). The role of emotional intelligence in education. The Springer series on Human Exceptionality, DOI 10.1007/978-0-387-88370-7_13.

Parker, J., Duffy, J., Wood, L., Bond, B., \& Hogan, M. (2005). Academic achievement and emotional intelligence: Predicting the successful transition from high school to university. Journal of the First-Year Experience \& Students in Transition, 17, 67-78.

Parker, J., Creque, R., Barnhart, D., Harris, J., Majeski, S., Wood, L., Bond, B., \& Hogan, M. (2004). Academic achievement in high school: Does emotional intelligence matter?. Personality and Individual Differences, 37, 1321-1330.

Parveen, A., Malik, M., \& Aziz, R. (2012). Emotional intelligence and academic achievement of male and female adolescent students of district Budgam. Journal of Education \& Practice, 3, 184-186.

Petrides, K., Frederickson, N., \& Furnham, A. (2004). The role of trait emotional intelligence in academic performance and deviant behavior at school. Personality and Individual Differences, 36, 277-293.

Pope, D., Roper, C., \& Qualter, P. (2012). The influence of emotional intelligence on academic progress and achievement in UK university students. Assessment \& Evaluation in Higher Education, 37, 907-918.

Preeti, B. (2013). Role of emotional intelligence for academic achievement for students. Research Journal of Educational Sciences, 1, 8-12.

Ramazan, M., Gujjar, A., \& Ahmad, S. (2011). Impact of emotional intelligence on academic achievement of perspective teachers in the subject of English. Language in India: Strength for Today and Bright Hope for Tomorrow, 11(5), 272-283.

Rode, J., Mooney, C., Arthaud-Day, M., Near, J., Baldwin, T., Rubin, R., \& Bommer, W. (2007). Emotional intelligence and individual performance: Evidence of direct and moderated effects. Journal of Organizational Behavior, 28, 399-421.

Salvia, J., \& Ysseldyke, J. (2000). Assessment (8th edition). New York: Houghton Mifflin.

Sanchez-Nunez, M. T., Fernandez-Berrocal, P., Montanes, J., \& Latorre, J. M. (2008). Does emotional intelligence depend on gender? The socialization of emotional competencies in men and women and its implications. Electronic Journal of Research in Educational Psychology, 6(2), 455-474.

Shuttes, N., Schuetplez, E., \& Malouff, J. (2001). Emotional intelligence and task performance. Imagination, Cognition and Personality, 20, 347-354.

Stys, Y., \& Brown, S. (2004). A review of the emotional intelligence literature and implications for corrections (Research Report No.R-150). Ontario: Correctional Service of Canada.

Sunil, K., \& Rooprai, K. (2009). The role of emotional intelligence in managing stress and anxiety at workplace. ASBBS Annual Conference (pp. 1-12), Las Vegas, February.

Svetlana, H. (2007). Emotional intelligence and academic achievement in higher education. Pepperdine University. 
Walker, M. (2006). Emotional intelligence and academic success in college (Unpublished doctoral dissertation, The University of Southern Mississippi).

Wong, C., \& Law, K. (2002). The effects of leader and follower emotional intelligence on performance and attitude: Exploratory study. The Leadership Quarterly, 13, 243- 274.

Yahaya, A., Sar, N., Bachok, J., Yahaya, N., Boon, Y., Hashim, S., \& Lee, G. (2012). The impact of emotional intelligence element on academic achievement. Archives Des Sciences, 65, 2-17. 